\title{
BMJ
}

\section{Parent initiated prednisolone for acute asthma in children of school age: randomised controlled crossover trial}

P J Vuillermin, paediatrician, ${ }^{1,2,4}$ C F Robertson, director of the department of respiratory medicine, ${ }^{2,3,4}$
J B Carlin, director of the clinical epidemiology and biostatistics unit, ${ }^{3,2,4} \mathrm{~S}$ L Brennan, national health and medical
research council scholar, ${ }^{1}$ M I Biscan, research nurse, ${ }^{1}$ M South, director of the department of general medicine ${ }^{2,3,4}$

${ }^{1}$ Geelong Hospital, Barwon Health, Geelong 3220, Australia

${ }^{2}$ The Royal Children's Hospital, Melbourne, Victoria 3052, Australia

${ }^{3}$ The Murdoch Children's Research Institute, Parkville, Victoria 3052, Australia

${ }^{4}$ University of Melbourne, Parkville, Victoria 3052, Australia

Correspondence to: PJ Vuillermin peterv@barwonhealth.org.au

Cite this as: BMJ 2010;340:c843 doi:10.1136/bmi.c843

\section{ABSTRACT}

Objective To evaluate the efficacy of a short course of parent initiated oral prednisolone for acute asthma in children of school age.

Design Double blind, randomised, placebo controlled, crossover trial in which episodes of asthma, rather than participants, were randomised to treatment.

Setting The Barwon region of Victoria, Australia.

Participants Children aged 5-12 years with a history of recurrent episodes of acute asthma.

Intervention A short course of parent initiated treatment with prednisolone (1 $\mathrm{mg} / \mathrm{kg}$ a day) or placebo.

Main outcome measures The primary outcome measure was the mean daytime symptom score over seven days. Secondary outcome measures were mean night time symptom score over seven days, use of health resources, and school absenteeism.

Results 230 children were enrolled in the study. Over a three year period, 131 (57\%) of the participants contributed a total of 308 episodes of asthma that required parent initiated treatment: 155 episodes were treated with parent initiated prednisolone and 153 with placebo. The mean daytime symptom score was 15\% lower in episodes treated with prednisolone than in those treated with placebo (geometric mean ratio $0.85,95 \% \mathrm{Cl} 0.74$ to 0.98 ; $\mathrm{P}=0.023)$. Treatment with prednisolone was also associated with a $16 \%$ reduction in the night time symptom score (geometric mean ratio $0.84,95 \% \mathrm{Cl} 0.70$ to 1.00 ; $\mathrm{P}=0.050$ ), a reduced risk of health resource use (odds ratio $0.54,95 \% \mathrm{Cl} 0.34$ to $0.86 ; \mathrm{P}=0.010)$, and reduced school absenteeism (mean difference -0.4 days, $95 \% \mathrm{Cl}-0.8$ to 0 . 0 days; $P=0.045$ ).

Conclusion A short course of oral prednisolone initiated by parents when their child experiences an episode of acute asthma may reduce asthma symptoms, health resource use, and school absenteeism. However, the modest benefits of this strategy must be balanced against potential side effects of repeated short courses of an oral corticosteroid.

Trial registration ISRCTN 26232583.

\section{INTRODUCTION}

Acute asthma is one of the leading causes of emergency department presentation and hospital admission worldwide. ${ }^{1}$ Strategies to reduce the burden of symptoms related to acute asthma and cut health resource use are clearly needed. There is high level evidence that oral corticosteroids are effective in the treatment of acute asthma in children of school age when administered after the child has been assessed by a doctor. ${ }^{2}$

Many of the benefits of oral corticosteroids have been shown to begin within three hours of administration, ${ }^{3}$ and delayed dosing is less effective at resolving acute asthma. ${ }^{4}$ Incorporating parent initiation of oral corticosteroids into the education and action plans for acute asthma that doctors provide families may be an effective way to ensure oral corticosteroid therapy is initiated promptly when a child suffers an episode of acute asthma. However, a strategy of parent initiated oral corticosteroids is likely to result in higher levels of administration of corticosteroids to children with asthma. This issue is of concern because in addition to their immediate effects on behaviour ${ }^{5}$ and adrenal function, ${ }^{6}$ oral corticosteroids are linked with reduced adult height in children with asthma. ${ }^{7}$ For example, as few as five short courses of oral corticosteroids over a seven year period during childhood has been associated with diminished bone mineral accrual. ${ }^{8}$ Therefore, the potential benefits of parent initiated oral corticosteroids require careful evaluation.

Parent initiated treatment with oral corticosteroids seems to be ineffective among preschool children with so called "viral induced wheeze," and the European Respiratory Society recently advised against parent initiated oral corticosteroids in children of preschool age with recurrent wheeze. ${ }^{10}$ Existing evidence regarding parent initiated oral corticosteroids in school age children with asthma is inadequate, ${ }^{11}$ and the role of parent initiation of oral corticosteroids is not clarified in international asthma management guidelines. ${ }^{12} 13$ None the less, parent initiated oral corticosteroids are widely used in clinical practice. ${ }^{14}$

We undertook a double blind, randomised, crossover trial to determine the effectiveness of parent initiated oral prednisolone compared with placebo in children of primary school age who experience recurrent episodes of acute asthma. 


\section{METHODS}

\section{Patients}

This single centre population based study was conducted in the Barwon region of Victoria, Australia. Children aged 5 to 12 years who had experienced four or more episodes of acute asthma requiring at least 24 hours of bronchodilator therapy in the preceding 12 months were eligible to participate, regardless of the presence or absence of asthma interval symptoms. We judged that these criteria could be applied in a general practice setting and would identify children likely to have further episodes of acute asthma.

We conducted a survey among parents to determine the prevalence of asthma symptoms in children at primary school in the Barwon region and included a request for respondents to volunteer their contact details. ${ }^{15}$ Parents who reported that their child had experienced four or more episodes of wheeze during the preceding 12 months were contacted and underwent a structured telephone interview designed to identify children likely to meet the trial eligibility criteria. We also identified potential participants via the Geelong Hospital. Potential participants then underwent an assessment with a single paediatrician (PJV) to determine eligibility.

\section{Procedures}

We randomised episodes of acute asthma, rather than participants. Participants were randomly assigned to one of four sequences of study medication $(\mathrm{ABAB}$, $\mathrm{ABBA}, \mathrm{BAAB}$, or $\mathrm{BABA}$, where $\mathrm{A}=$ prednisolone and $\mathrm{B}=$ placebo). Each discrete episode of acute asthma was treated with one or the other of the parent initiated study medications (A or B) in the sequence specified. Participants were able to contribute a maximum of eight episodes of acute asthma to data collection.

The hospital pharmacist stored the sequence codes and dispensed the study medication for the first episode at the time of enrolment and subsequent medications after each episode according to the assigned sequence. The prednisolone solution we used was Redipred (Aspen Pharmacare Pty Ltd; Saint Leonards, NSW, Australia), which contains $6.72 \mathrm{mg} / \mathrm{ml}$ of the active ingredient, prednisolone sodium phosphate. The placebo solution was also manufactured by the makers of Redipred; however, the hospital pharmacist added $0.1 \%$ quinine bisulphate to the placebo mixture to mimic the bitter taste of prednisolone. The bottles of prednisolone and placebo appeared identical. We used a once daily dose of $1 \mathrm{mg}$ per $\mathrm{kg}$ in dosing intervals of $10 \mathrm{mg}$ (that is, 10, 20, 30, 40, or $50 \mathrm{mg}$ ). Any doctor could substitute the study medication with an oral corticosteroid if they deemed it appropriate because of worsening or persisting symptoms. Children in the study were given parent initiated prednisolone or placebo in addition to their standard treatment.

Episodes of acute asthma were defined by the following advice given to parents: "If from previous experience you suspect this is a more severe attack, or if the symptoms are not getting better in about 6 to 8 hours with regular use of reliever medication, give your child the study medication immediately." Parents were instructed to continue to administer the study medication for three to five days depending on the persistence or resolution of their child's asthma symptoms. To ensure an adequate washout period and that the episodes were discrete, parents were instructed not to commence a course of study medicine until a minimum of 14 days after starting the previous treatment and seven days after stopping a previous course of study medication or oral corticosteroids. Parents were instructed not to increase the dose of inhaled corticosteroid (if applicable) during an exacerbation.

During the enrolment process, a personalised asthma management plan was developed for each participant in accordance with the local asthma management guidelines. ${ }^{16} \mathrm{We}$ sought to ensure that the use or non-use of any additional asthma preventive medications was appropriate, that an appropriate drug delivery device was being used effectively, that there was a sound understanding of dosing (including the fact that for children older than 6 years it was appropriate to deliver up to 12 actuations $(1200 \mu \mathrm{g})$ of salbutamol at a time), and that the families understood the criteria for seeking a medical review. Parents were instructed to seek a medical review: (1) if their child had a bad attack or they were worried; (2) if their child needed salbutamol more than every 3 hours; (3) if their child was getting little or no relief from salbutamol; or (4) if wheezing lasted more than 24 hours and was not getting better.

The participant's atopic status was determined via skin prick testing in accordance with standard guidelines. ${ }^{17}$ The physician conducting enrolment (PJV) recorded a subjective impression of the parent's competence with asthma management on a five point scale. Adherence was determined by correlating the parent's report with the amount of study medication remaining when data collection was complete.

The primary outcome measure was mean daytime symptom score over seven days according to the paediatric asthma diary ${ }^{18}$ (table 1). This daytime symptom score was chosen because it is a well validated instrument for measuring a child's experience of acute asthma. Secondary outcome measures were the mean night time symptom score, health resource use, asthma-free days (daytime symptom score of zero), days of school missed, days of work missed by the parent(s), and substitution of the study medication with an oral corticosteroid following a medical review. Health resource use was a dichotomous outcome defined by the occurrence of a local doctor, paediatrician, or emergency department review for acute asthma during the seven days after initiation of the study medication. Symptom scores, health resource use, and behavioural changes were documented in the diaries.

\section{Statistical analysis}

We conducted a log scale sample size calculation ${ }^{19}$ to determine how many episodes of acute asthma would be required to detect a $20 \%$ reduction in the mean daytime symptom score, basing the anticipated mean and 
Table 1| Daytime and night time symptom score diary ${ }^{18}$

\begin{tabular}{|c|c|c|c|c|c|c|}
\hline Daytime & Please fill this out bef & going to bed & & & & \\
\hline $\begin{array}{l}\text { How much of the time did you have } \\
\text { trouble breathing today? }\end{array}$ & None of the time & A little of the time & Some of the time & A good bit of the time & Most of the time & All of the time \\
\hline Circle one number & 0 & 1 & 2 & 3 & 4 & 5 \\
\hline $\begin{array}{l}\text { How much did your asthma bother } \\
\text { you today? }\end{array}$ & Did not bother me & Bothered me a little & $\begin{array}{l}\text { Bothered me } \\
\text { somewhat }\end{array}$ & $\begin{array}{l}\text { Bothered me a good } \\
\text { deal }\end{array}$ & Bothered me very much & $\begin{array}{l}\text { Bothered me as much as } \\
\text { possible }\end{array}$ \\
\hline Circle one number & 0 & 1 & 2 & 3 & 4 & 5 \\
\hline $\begin{array}{l}\text { How much of the time did your } \\
\text { asthma limit your activity today? }\end{array}$ & None of the time & A little of the time & Some of the time & A good bit of the time & Most of the time & All of the time \\
\hline Circle one number & 0 & 1 & 2 & 3 & 4 & 5 \\
\hline Night time & Please fill this out in $t$ & orning & & & & \\
\hline $\begin{array}{l}\text { Were you woken by asthma? (either } \\
\text { during the night or in the morning) }\end{array}$ & No & Once & More than once & Awake all night & & \\
\hline Circle one number & 0 & 1 & 2 & 3 & & \\
\hline
\end{tabular}

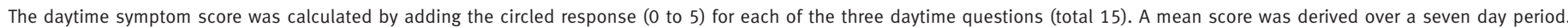
The night time symptom score was calculated from the response ( 0 to 3 ) to the single night time question. A mean score was derived over a seven night period.

variance of the daytime symptom score on previous publications ${ }^{18}$ and using an alpha value of 0.05 with a power value of 0.9 . This calculation indicated that we would require 154 episodes of acute asthma per treatment group to ensure the study would be sufficiently powered. The trial statistician (JBC) conducted a preplanned and blinded interim analysis when data on 160 episodes of acute asthma had been collected. The difference between treatment groups in daytime symptom score and health resource use was insufficient to meet the Haybittle-Peto stopping rule. ${ }^{20}$

All episodes of acute asthma that resulted in the participant receiving at least one dose of the study medication were included in the analyses for health resource use. For each of the diary derived outcomes, however, we included only diaries in which all the items relevant to the calculation of the given outcome were completed. The daytime symptom score and night time symptom score were analysed in a log scale, with comparisons reported as geometric mean ratios. Analyses were performed using generalised estimating equations to allow for correlation among repeated observations collected from participants contributing multiple episodes of acute asthma. ${ }^{21}$ Dichotomous outcomes such as health resource use were compared between treatment arms, with odds ratios obtained from logistic regression models fitted using the generalised estimating equations method. Analyses were performed with Stata, version 10 (Stata Corporation; Austin, TX).

\section{RESULTS}

Two hundred and five children were identified via the asthma survey and were enrolled between 8 March and 18 September 2005. A further 25 eligible participants were identified by presentation to the Geelong Hospital during the course of the trial. The recruitment, randomisation, and follow-up of participants are shown in figure 1.

Approximately 340 children in the Barwon region would have met the study eligibility criteria. Thus, we estimate that the 230 children who participated in the study represented greater than $60 \%$ of those who were eligible in the region. Of the 230 children who were randomly assigned treatment, $225(98 \%)$ stayed in the study until data collection was completed. The mean period for which participants were eligible to contribute episodes was 2 years and 9 months.

Between 14 March 2005 and 24 May 2008, 131 $(57 \%)$ of the 230 participants contributed a total of 308 episodes of asthma that required parent initiated treatment with the study medication. The baseline characteristics of the 131 participants who contributed episodes are shown in table 2 . At the time of enrolment, almost half $(56 / 131(43 \%))$ of the participants who contributed episodes reported asthma interval symptoms (more than one disturbed night per week; difficulty participating in physical activities; or bronchodilator use on more than one day per week). Two thirds $(89 / 131(68 \%))$ had been prescribed an asthma preventive medication for regular use, in accordance with current asthma management guidelines.

The numbers of episodes contributed per participant were as follows: 55 participants contributed one episode; 29 contributed two; 23 contributed three; nine contributed four; eight contributed five; one contributed six; four contributed seven; and two contributed eight. Only seven participants contributed more than two episodes a year. All the daytime symptom score items in the symptom diary were completed for 140 $(90 \%)$ of the 155 episodes treated with prednisolone and $136(89 \%)$ of the 153 of the episodes treated with placebo. Complete data on health resource use were available for all 308 episodes. As a result of the trial's crossover design, the baseline characteristics of the participants were similarly distributed between episodes treated with prednisolone and those treated with placebo.

\section{Outcomes}

The differences between episodes treated with prednisolone and those treated with placebo in asthma symptom scores, asthma-free days, and missed days of school and work are summarised in table 3 . The daytime symptom score was 15\% lower in episodes treated 
Table 2 | Baseline characteristics of participants who contributed episodes

\begin{tabular}{|c|c|c|c|c|c|}
\hline & \multicolumn{2}{|c|}{$\begin{array}{l}\text { All participants who contributed } \\
\text { episodes }(n=131)\end{array}$} & \multicolumn{2}{|c|}{$\begin{array}{l}\text { Participants who contributed } \\
\text { a single episode only }(n=55)\end{array}$} & \multirow{2}{*}{$\begin{array}{l}\text { Participants who } \\
\text { contributed more than } \\
\text { one episode }(n=76)\end{array}$} \\
\hline & At enrolment & At study completion & Prednisolone $(n=27)$ & Placebo $(n=28)$ & \\
\hline Age (mean (SD)) in years & $7.9(2.1)$ & $10.6(2.3)$ & $8.0(2.3)$ & 7.7 (1.9) & $7.9(2.1)$ \\
\hline Male sex & $89(69)$ & - & $20(71)$ & $20(74)$ & $49(64)$ \\
\hline Atopic sensitisation & $94(72)$ & - & $20(74)$ & $23(82)$ & $51(67)$ \\
\hline History of eczema & $76(58)$ & - & $16(59)$ & $18(64)$ & $42(55)$ \\
\hline Asthma interval symptoms & $56(43)$ & $50(38)$ & $11(41)$ & $13(46)$ & $32(42)$ \\
\hline Prescribed regular use of an asthma preventive & $89(68)$ & $59(45)$ & $19(70)$ & $22(79)$ & $48(63)$ \\
\hline
\end{tabular}

Values are numbers (percentages) unless otherwise indicated.

with parent initiated prednisolone than in those treated with placebo (geometric mean ratio $0.85,95 \%$ CI 0.74 to $0.98 ; \mathrm{P}=0.023)$. A similar reduction was seen in the night time symptom score, but the statistical evidence was slightly weaker (geometric mean ratio $0.84,95 \%$ CI 0.70 to $1.00 ; \mathrm{P}=0.05)$. There was little evidence for a difference between treatment groups in the number of asthma-free days (mean difference 0.3 days, 95\% CI

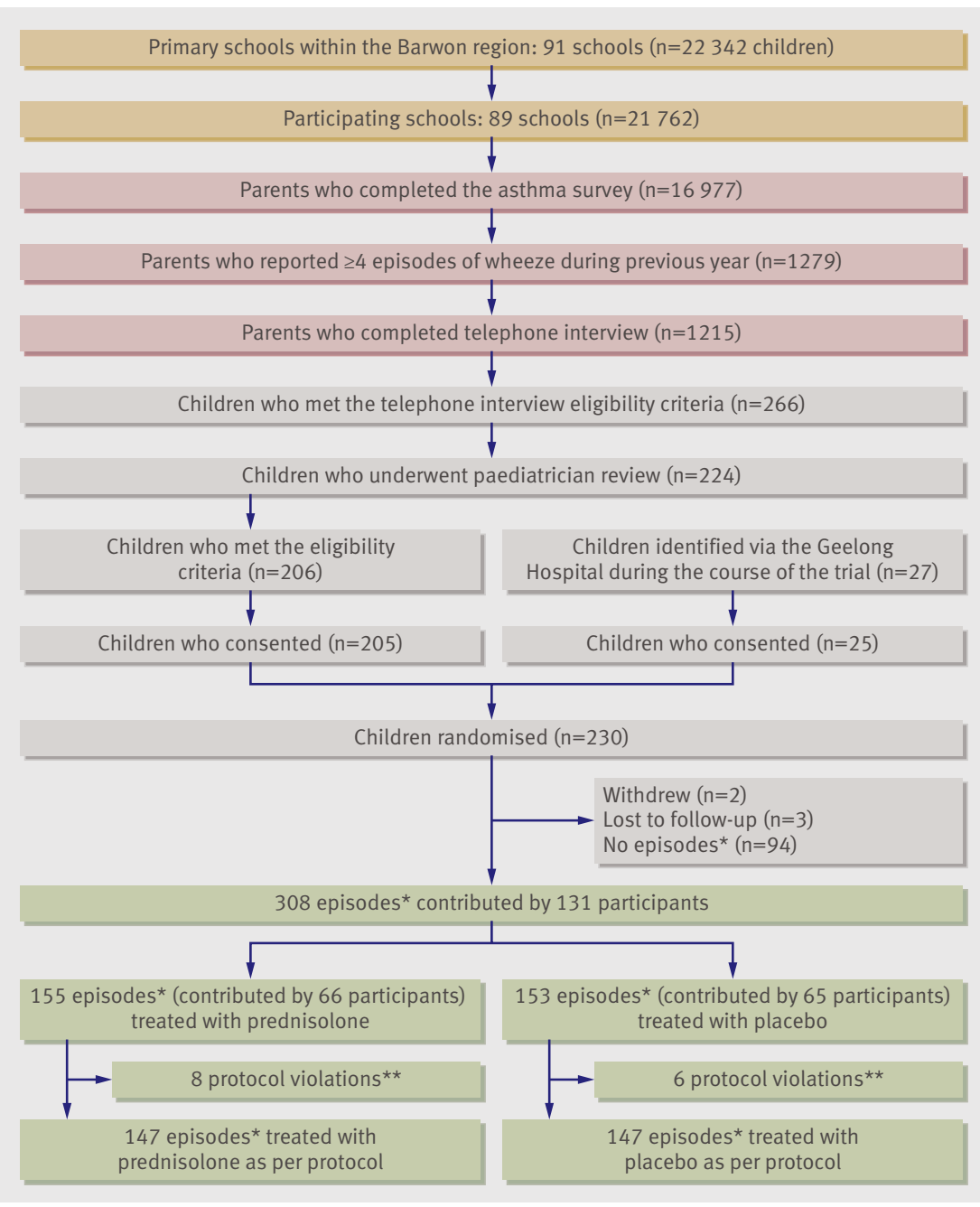

Fig 1 | Flowchart of recruitment, randomisation, and follow-up of participants and episodes *Episodes=episodes of acute asthma for which the parent initiated treatment with the study medication. ${ }^{* *}$ In each case the protocol violation consisted of ceasing the trial medication early because symptoms had improved (without substitution for a known oral corticosteroid)
-0.1 to 0.6 days; $\mathrm{P}=0.124$ ). Children missed fewer days of school for episodes treated with prednisolone than for those treated with placebo (mean difference -0.4 days, $95 \%$ CI -0.8 to 0.0 days; $\mathrm{P}=0.045)$, but there was no difference in the amount of work missed by parents (mean difference -0.1 days, $95 \% \mathrm{CI}-0.4$ to 0.3 days; $\mathrm{P}=0.765)$. There was no evidence that the effect of prednisolone compared with placebo on daytime symptom score and health resource use was greater in any particular subgroup (fig 2).

The rates of asthma related health resource use and substitution of the study medication with an oral corticosteroid are summarised in table 4. Episodes of asthma treated with prednisolone were less likely to result in use of health resources than episodes treated with placebo (odds ratio $0.54,95 \%$ CI 0.34 to $0.86 ; \mathrm{P}=0.010$ ). The majority of this difference was owing to a reduced rate of local doctor review for episodes treated with prednisolone. There was also some evidence that treatment with prednisolone was associated with a reduced risk of hospital admission (odds ratio $0.41,95 \%$ CI 0.16 to $1.05 ; \mathrm{P}=0.064)$, but the estimated number of episodes needed to treat was greater than 20 with a broad confidence interval $(25,95 \%$ CI 10.07 to $\infty)$.

Episodes treated with parent initiated prednisolone were less likely than those treated with placebo to result in substitution of the study medication with an oral corticosteroid following a medical review (odds ratio $0.44,95 \%$ CI 0.26 to $0.73 ; \mathrm{P}=0.002)$. With regard to episode severity (and thus the appropriateness of the parent's decision to initiate therapy), only $11(7 \%)$ of the 153 placebo treated episodes resolved within three days, whereas 69 (45\%) required health resource use (local doctor, paediatrician, or emergency department review). In $54(78 \%)$ of these 69 cases, the study medication was substituted for a known oral corticosteroid. There was no difference in the rate of behavioural adverse effects between treatment groups.

The difference between treatment groups appeared to be unrelated to the number of episodes contributed by participants. Among participants who contributed two or fewer episodes, treatment with prednisolone was associated with an $18 \%$ reduction in the daytime symptom score (ratio of geometric means $0.82,95 \%$ CI 0.63 to 1.09 ) and an odds ratio for health resource use of $0.53(95 \%$ CI 0.25 to 1.10$)$. In participants who contributed more than two episodes, treatment with prednisolone was associated with a $15 \%$ reduction in 
the daytime symptom score (ratio of geometric means $0.85,95 \%$ CI 0.73 to 0.99 ) and an odds ratio for health resource use of 0.55 (95\% CI 0.31 to 1.00$)$.

\section{DISCUSSION}

\section{Principal findings of the study}

This study found that, for children of school age with a history of frequent episodes of acute asthma, a short course of oral prednisolone initiated by parents early in the course of an episode of acute asthma was associated with a modest reduction in asthma symptoms, health resource use, and school absenteeism.

Several aspects of the methodology of this trial were novel. For example, we used a single centre, population based approach; by contrast, the vast majority of large scale interventional trials are undertaken at multiple centres. Although the multicentre approach facilitates recruitment, the single centre approach enabled us to foster a sense of community "ownership" over the project, which was invaluable in developing and maintaining participant involvement.

Our recruitment strategy was also novel. Our approach of combing a population based survey of asthma symptoms ${ }^{15}$ and requesting that parents volunteer their contact details allowed us to efficiently identify and recruit approximately $60 \%$ of the relevant children in the Barwon region. This survey also provided data on both the participants and their source population, which assisted with interpreting the generalisability of the study findings. The strategy of randomly allocating episodes of acute asthma rather than participants was also effective because the within participant data reduced the diluting effect of between participant variation in asthma phenotype, symptom interpretation, and threshold for health resource use.

Table 3|Symptom scores, asthma-free days, days of school missed by the participant, and days of work missed by the parent

\begin{tabular}{|c|c|c|c|c|}
\hline & $\begin{array}{c}\text { Number (\%) of diaries } \\
\text { with relevant items } \\
\text { completed }\end{array}$ & Mean (SD) & $\begin{array}{l}\text { Ratio or difference* } \\
\qquad(95 \% \mathrm{Cl})\end{array}$ & $P$ value \\
\hline \multicolumn{5}{|c|}{ Daytime symptom score* } \\
\hline Prednisolone & $140 / 155(90)$ & $1.19(0.74)$ & 0.85 (0.74 to 0.98$)$ & 0.023 \\
\hline Placebo & $136 / 153(89)$ & $1.35(0.67)$ & 一 & - \\
\hline \multicolumn{5}{|c|}{ Night time symptom score* } \\
\hline Prednisolone & $141 / 155(91)$ & $-0.77(1.00)$ & $0.84(0.7$ to 1.0$)$ & 0.050 \\
\hline Placebo & $137 / 153(90)$ & $-0.54(0.84)$ & - & - \\
\hline \multicolumn{5}{|l|}{ Asthma-free days } \\
\hline Prednisolone & $141 / 155(91)$ & $1.8(1.8)$ & $0.3(-0.1$ to 0.6$)$ & 0.124 \\
\hline Placebo & $139 / 153(91)$ & $1.5(1.7)$ & - & - \\
\hline \multicolumn{5}{|c|}{ Days of school missed by the participant } \\
\hline Prednisolone & $150 / 155(97)$ & $1.8(1.9)$ & $-0.4(-0.8$ to 0.0$)$ & 0.045 \\
\hline Placebo & $147 / 153(96)$ & $2.2(2.2)$ & 一 & - \\
\hline \multicolumn{5}{|c|}{ Days of work missed by the parent } \\
\hline Prednisolone & $131 / 155(85)$ & $0.7(1.4)$ & $-0.1(-0.4$ to 0.3$)$ & 0.765 \\
\hline Placebo & $131 / 153(86)$ & $0.8(1.4)$ & - & - \\
\hline
\end{tabular}

*Mean and standard deviation (SD) for daytime symptom scores and night time symptom scores were calculated from natural log values, whereas the comparisons were back transformed to give geometric mean ratios comparing prednisolone with placebo. To ensure non-negative values for log transformation, one half of the minimum score $(1 / 14=0.071)$ was added to the night time symptom scores before transformation.

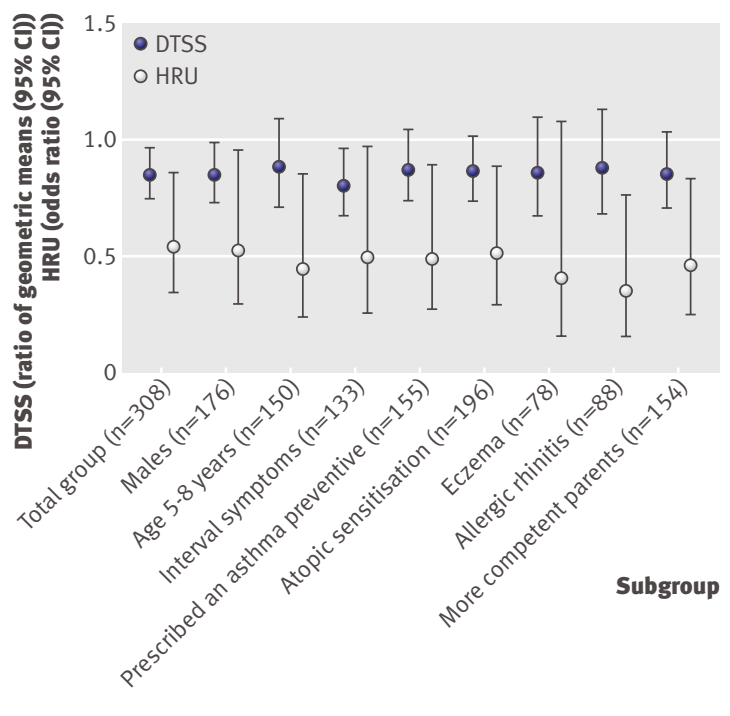

Fig 2 | Subgroup analysis of the effect of prednisolone compared with placebo on daytime symptom score (DTSS) and health resource use (HRU). n=number of episodes treated with study medication where participants had the given subgroup characteristic

\section{Comparison with other studies}

Two previous randomised controlled trials found no benefit associated with parent initiated oral corticosteroids. The first study, by Grant et al, ${ }^{22}$ evaluated a single $2 \mathrm{mg}$ per $\mathrm{kg}$ dose of prednisolone administered by parents at the onset of wheezing in 86 children with a diagnosis of "asthma." The participants were aged 2 to 14 years, but most were less than 6 years of age. They were observed for a 12 month period: during one six month period the study medication was prednisolone, during the other it was placebo. Surprisingly, the likelihood of health resource use was greater during the six months where the study medication was prednisolone. There were no differences between treatment periods in the other measured outcomes.

The second study, by Oommen et al, ${ }^{9}$ evaluated in children aged 1 to 5 years the efficacy of $20 \mathrm{mg}$ prednisolone a day for five days administered by parents at the onset of an episode of wheeze. A total of 217 children were enrolled and data were collected on 121 wheeze episodes. There was no difference between treatment groups in symptom scores, health resource use, substitution of the study medication, or other outcome measures.

There are several reasons why we observed a benefit from parent initiated oral corticosteroids whereas previous trials on parent led oral corticosteroid use have not. ${ }^{922}$ Most notably, the children included in this study were of school age, whereas most of the participants in the previous trials on parent initiated oral corticosteroids were of preschool age. ${ }^{922}$ There is good evidence that oral corticosteroids are effective in school age children with asthma, ${ }^{2}$ whereas recent evidence suggests that oral corticosteroids may not be effective among preschool children with virus induced wheezing. ${ }^{23}$ 
Table $4 \mid$ Health resource use and study medication substitution

\begin{tabular}{|c|c|c|c|c|c|}
\hline Outcome & $\begin{array}{l}\text { Prednisolone } \\
\qquad(n=155)\end{array}$ & $\begin{array}{l}\text { Placebo } \\
(n=153)\end{array}$ & $\begin{array}{l}\text { Odds ratio } \\
(95 \% \mathrm{Cl})\end{array}$ & $P$ value & $\begin{array}{c}\text { Number of episodes } \\
\text { needed to treat }(95 \% \mathrm{Cl})\end{array}$ \\
\hline Local doctor review* & $36 / 155(23 \%)$ & $53 / 153(35 \%)$ & $0.57(0.35$ to 0.92$)$ & 0.022 & $8.3(4.5$ to 50.0$)$ \\
\hline Emergency department review* & $15 / 155(10 \%)$ & $21 / 153(14 \%)$ & $0.67(0.33$ to 1.34$)$ & 0.254 & $25(9.1$ to $\infty)$ \\
\hline Hospital admission* & $6 / 155(4 \%)$ & $12 / 153(8 \%)$ & $0.41(0.16$ to 1.05$)$ & 0.064 & $25(10.7$ to $\infty)$ \\
\hline Health resource use $\dagger$ & $48 / 155(31 \%)$ & $69 / 153(45 \%)$ & $0.54(0.34$ to 0.86$)$ & 0.010 & 7.1 (4.0 to 30.3$)$ \\
\hline \multicolumn{6}{|l|}{ Study medication substitution } \\
\hline Study medication changed to an oral corticosteroid following a medical review & $30 / 155$ (19\%) & $54 / 153(35 \%)$ & $0.44(0.26$ to 0.73$)$ & 0.002 & $6.2(3.9$ to 16.1$)$ \\
\hline $\begin{array}{l}\text { Study medication changed to an oral corticosteroid because episode resulted } \\
\text { in health resource use }\end{array}$ & $30 / 48(63 \%)$ & $54 / 69(78 \%)$ & $0.44(0.21$ to 0.95$)$ & 0.047 & - \\
\hline
\end{tabular}

*Local doctor review, emergency department review, and hospital admission are not reported as mutually exclusive outcomes.

†Health resource use comprises local doctor, paediatrician, or emergency department review.

It may also be relevant that we emphasised coadministration of high doses of $\beta$ agonists. The early effects of oral corticosteroids are partly owing to upregulation of $\beta$ receptors on the surface of airway smooth muscle, rather than anti-inflammatory action. ${ }^{2425}$ In the previous trials on parent initiated oral corticosteroids, the recommended dose of $\beta$ agonist was either lower than that used in our trial (up to $400 \mu \mathrm{g}$ of salbutamol) ${ }^{9}$ or not specified. ${ }^{22}$

Finally, our study had greater statistical power than previous studies because we collected data on a higher number of episodes and our data were paired.

\section{Study limitations}

Limitations to this study include not measuring the severity of the episodes of acute asthma or the appropriateness of the parent's decision to initiate the study medication. We were unable to measure directly episode severity because of the study's pragmatic design. Our objective was to determine the effectiveness of a healthcare strategy (parent initiated oral corticosteroids) rather than the efficacy of a therapeutic agent (prednisolone).

A crucial aspect of parent initiation of oral corticosteroids is that the parent must make the decision to initiate treatment without the assistance of a health professional to help evaluate episode severity. We judged that attempting to measure objectively episode severity at the time of oral corticosteroid initiation would undermine the study objective. It is possible that the effect of prednisolone was diluted by the inclusion of data from episodes where the parent initiated treatment without an adequate indication. It should be noted, however, that $69(45 \%)$ of the 153 placebo treated episodes resulted in health resource use. In $54(78 \%)$ of these 69 instances, the study medication was substituted by the treating doctor for a known oral corticosteroid, indicating that many of the episodes were not trivial.

We also did not measure the participants' lung function. Paediatric lung function testing is not available to most general practitioners. Given that parent initiated use of oral corticosteroids is a strategy that is particularly relevant to general practitioners, it was our view that the study eligibility criteria should reflect parameters that might be readily applied in the general practice setting.

\section{Conclusions and policy implications}

The results of this study are important because there has been minimal previous success in identifying parent initiated strategies that may reduce the burden of acute asthma in children. One of the approaches that has been evaluated is administration of a short course of inhaled corticosteroids. Although there is some evidence that high dose inhaled corticosteroids may be effective in the treatment of acute asthma in the hospital setting ${ }^{26}$ and may also be associated with modest benefit in the ambulatory setting, ${ }^{27}$ high dose inhaled corticosteroids are not as effective as oral corticosteroids..$^{28}$

A second approach is the use of formulations containing an inhaled corticosteroid and a long acting $\beta$ agonist. Among children with uncontrolled asthma, the use of inhaled corticosteroids and a long acting $\beta$ agonist as both maintenance and reliever medication may reduce asthma related health resource use compared with fixed dose inhaled corticosteroids and a long acting $\beta$ agonist as maintenance treatment only. ${ }^{29}$ However, fewer than $15 \%$ of children who present to an emergency department with an episode of acute asthma have a background of uncontrolled asthma ${ }^{30}$; therefore, maintenance and reliever treatment with inhaled corticosteroids and a long acting $\beta$ agonist is not appropriate for the great majority of children likely to use health resources to relieve acute asthma.

A third option is the use of a short course of the leukotriene receptor antagonist montelukast. There is evidence that parent initiated montelukast in children of preschool age with intermittent asthma is associated with a reduction in asthma symptoms and health resource use. ${ }^{31}$ The magnitude of benefit is similar to that seen with parent initiated oral corticosteroids in this study. The evidence regarding short course montelukast in the treatment of acute asthma in school age children is inadequate, however, and there are no head to head trials comparing short course montelukast with oral corticosteroids for acute asthma in any age group.

What, then, is the role of parent initiated oral corticosteroids in the management of childhood asthma? From a health resource viewpoint, the use of parent initiated oral corticosteroids is cheap and seems to be associated with an important reduction in health resource use, which is costly. From the patient's viewpoint, however, the symptom benefit is modest, and a relatively large 


\section{WHAT IS ALREADY KNOWN ON THIS TOPIC}

High level evidence indicates that oral corticosteroid therapy initiated by a doctor in the hospital setting is effective in the treatment of acute asthma in children of school age

Existing evidence regarding the efficacy of parent initiated oral corticosteroids in children of school age with asthma is inadequate

\section{WHAT THIS STUDY ADDS}

Among children of school age, a short course of oral prednisolone initiated by parents for episodes of acute asthma may result in a reduction in asthma symptoms, health resource use, and school absenteeism

The modest benefits of this strategy must be balanced against potential side effects of repeated short courses of an oral corticosteroid number of episodes will have to be treated to prevent the need for a medical review or hospital admission. In addition, the detrimental effects of recurrent short courses of oral corticosteroids may be significant. ${ }^{5-8}$ It seems sensible that if a child of school age has experienced repeated episodes of acute asthma that resulted in health resource use, the parent should be advised to keep oral corticosteroids available to be used in the event of a relatively severe episode. The clinician should, however, regularly review the frequency and appropriateness of parent initiated oral corticosteroids and health resource use to minimise the risk of adverse events related to the oral corticosteroids.

In summary, we found that in children of school age with a history of recurrent acute asthma, a short course of parent initiated oral prednisolone commenced early in the course of an episode of acute asthma is associated with a modest reduction in asthma related symptoms, health resource use, and school absenteeism. Parent initiated prednisolone may be an appropriate strategy for the management of more severe episodes of acute asthma in children of school age. However, the modest benefits of this strategy must be balanced against potential side effects of repeated courses of an oral corticosteroid.

We thank the primary schools in the Barwon region and the many families who participated. Paul Muir in the pharmacy department of Geelong Hospital coordinated the provision of study medication.

Contributors: PJV, MS, CFR, and JBC conceived and designed the study. PJV undertook study recruitment and assessments, supervised the research nurses, and had the major role in analysis and interpretation of the data and in drafting the report. JBC supervised the statistical analysis. SLB and MIB undertook study recruitment and cohort maintenance. All authors contributed significantly to drafting the report. All authors had full access to all the data in the study (including statistical reports and tables) and can take responsibility for the integrity of the data and the accuracy of the data analysis. PJV accepts full responsibility for this work and acts as the guarantor for the study.

Funding: PJV received scholarships from the Murdoch Childrens Research Institute and the National Health and Medical Research Council of Australia. The project was funded by the Jack Brockhoff Foundation, the Murdoch Childrens Research Institute, and the National Health and Medical Research Council of Australia. These funding bodies had no role in the collection, analysis, and interpretation of data; in the writing of the report; or in the decision to submit the article for publication.

Competing interests: All authors have completed the Unified Competing Interest form at www.icmje.org/coi_disclosure.pdf (available on request from the corresponding author) and declare (1) No financial support for the submitted work from anyone other than their employer; (2) No financial relationships with commercial entities that might have an interest in the submitted work; (3) No spouses, partners, or children with relationships with commercial entities that might have an interest in the submitted work; (4) No non-financial interests that may be relevant to the submitted work. CFR has been a member of advisory boards and has received lecture fees and educational grants from Merck, Sharp, \& Dohme and AstraZeneca, and has received a consultancy fee from Merck, Sharp, \& Dohme.

Ethical approval: Approval for the study was obtained from local ethics committees, and the parents of all participants signed an informed consent form.

Data sharing: Technical appendix, statistical code, and data set are available from the corresponding author at peterv@barwonhealth.org.au.

1 Bousquet J, Bousquet PJ, Godard P, Daures JP. The public health implications of asthma. Bull World Health Organ 2005;83:548-54.

2 Smith M, lqbal S, Elliott TM, Everard M, Rowe BH. Corticosteroids for hospitalised children with acute asthma. Cochrane Database Syst Rev 2003;1:CD002886.

3 Rubin BK, Marcushamer S, Priel I, App EM. Emergency management of the child with asthma. Pediatr Pulmonol 1990;8:45-57.

4 Streetman DD, Bhatt-Mehta V, Johnson CE. Management of acute severe asthma in children. Ann Pharmacother 2002;36:1249-60.

5 Kayani SSD. Adverse behavioural effects of treatment for acute exacerbation of asthma in children: a comparison of two doses of oral steroids. Chest 2002;122:624-8.

6 Zora JA, Zimmerman D, Carey TL, O’Connell EJ, Yunginger JW. Hypothalamic-pituitary-adrenal axis suppression after short-term, high-dose glucocorticoid therapy in children with asthma. J Allergy Clin Immunol 1986;77:9-13.

7 Allen DB, Mullen M, Mullen B. A meta-analysis of the effect of oral and inhaled corticosteroids on growth. J Allergy Clin Immunol 1994;93:967-76.

8 Kelly HW, Van Natta ML, Covar RA, Tonascia J, Green RP, Strunk RC. Effect of long-term corticosteroid use on bone mineral density in children: a prospective longitudinal assessment in the Childhood Asthma Management Program (CAMP) study. Pediatrics 2008;122:53-61.

9 Oommen A, Lambert PC, Grigg J. Efficacy of a short course of parentinitiated oral prednisolone for viral wheeze in children aged 1-5 years: randomised controlled trial. Lancet 2003;362:1433-8.

10 Brand PL, Baraldi E, Bisgaard H, Boner AL, Castro-Rodriguez JA, Custovic A, et al. Definition, assessment and treatment of wheezing disorders in preschool children: an evidence-based approach. Eur Respir J 2008;32:1096-110.

11 Vuillermin P, South M, Robertson C. Parent-initiated oral corticosteroid therapy for intermittent wheezing illnesses in children. Cochrane Database Syst Rev 2006;3:CD005311.

12 British Thoracic Society Scottish Intercollegiate Guidelines Network. British guideline on the management of asthma. Thorax 2008;63(suppl 4):1-121S.

13 National Asthma Education and Prevention Program. Expert panel report 3: guidelines for the diagnosis and management of asthmasummary report 2007. J Allergy Clin Immunol 2007;120(suppl 5):94-138S

14 Vuillermin PJ, South M, Carlin JB, Biscan MI, Brennan SL, Robertson CF. Parent-initiated oral corticosteroid therapy for acute asthma: a survey of current practice. J Paediatr Child Health 2007;43:443-5.

15 Vuillermin PJ, South M, Carlin JB, Biscan MI, Brennan SL, Robertson CF. Asthma among school children in the Barwon region of Victoria. Med J Aust 2007;187:221-4.

16 Asthma Strategy Group, Royal Children's Hospital Melbourne. Asthma best practice guidelines. 1999. www.rch.org.au/emplibrary/ clinicalguide/BPG-FINAL-260CT.pdf.

17 Bernstein IL, Storms WW. Practice parameters for allergy diagnostic testing. Joint Task Force on Practice Parameters for the Diagnosis and Treatment of Asthma. The American Academy of Allergy, Asthma and Immunology and the American College of Allergy, Asthma and Immunology. Ann Allergy Asthma Immunol 1995;75:543-625.

18 Santanello NC, Davies G, Galant SP, Pedinoff A, Sveum R, Seltzer J, et al. Validation of an asthma symptom diary for interventional studies. Arch Dis Child 1999;80:414-20.

19 Wolfe R, Carlin JB. Sample-size calculation for a log-transformed outcome measure. Control Clin Trials 1999;20:547-54.

20 Ellenberg SF, Fleming TR, DeMets DL. Data monitoring committees in clinical trials: a practical perspective. John Wiley, 2002.

21 Hanley JA, Negassa A, Edwardes MD, Forrester JE. Statistical analysis of correlated data using generalized estimating equations: an orientation. Am J Epidemiol 2003;157:364-75.

22 Grant CC, Duggan AK, DeAngelis C. Independent parental administration of prednisone in acute asthma: a double-blind, placebo-controlled, crossover study. Pediatrics 1995;96:224-9. 
23 Panickar J, Lakhanpaul M, Lambert PC, Kenia P, Stephenson T, Smyth A, et al. Oral prednisolone for preschool children with acute virus-induced wheezing. N EnglJ Med 2009;360:329-38.

24 Tan KS, Grove A, McLean A, Gnosspelius Y, Hall IP, Lipworth BJ. Systemic corticosteroid rapidly reverses bronchodilator subsensitivity induced by formoterol in asthmatic patients. Am J Respir Crit Care Med 1997;156:28-35.

25 Brodde OE, Howe U, Egerszegi S, Konietzko N, Michel MC. Effect of prednisolone and ketotifen on beta 2-adrenoceptors in asthmatic patients receiving beta 2-bronchodilators. Eur J Clin Pharmacol 1988;34:145-50.

26 Edmonds ML, Camargo CA Jr, Pollack CV Jr, Rowe BH. Early use of inhaled corticosteroids in the emergency department treatment of acute asthma. Cochrane Database Syst Rev 2003;3:CD002308.

27 Ducharme F, Lemire C, Noya F, Davis M. Preemptive use of high-dose fluticasone for virus-induced wheezing in young children. $N$ Engl Med 2009;360:339-53.
28 Schuh S, Dick PT, Stephens D, Hartley M, Khaikin S, Rodrigues L, et al. High-dose inhaled fluticasone does not replace oral prednisolone in children with mild to moderate acute asthma. Pediatrics 2006;118:644-50

29 Bisgaard H, Le Roux P, Bjamer D, Dymek A, Vermeulen JH, Hultquist C. Budesonide/formoterol maintenance plus relieve therapy: a new strategy in pediatric asthma. Chest 2006;130:1733-43.

30 Khan MS, O'Meara M, Henry RL. Background severity of asthma in children discharged from the emergency department. J Paediatr Child Health 2003;39:432-5.

31 Robertson CF, Price D, Henry R, Mellis C, Glasgow N, Fitzgerald D, et al. Short-course montelukast for intermittent asthma in children: randomized controlled trial. Am J Respir Crit Care Med 2007;175:323-9.

Accepted: 19 December 2009 